\title{
Blurring the Boundaries: Collaborative Library and Museum Exhibitions in Los Angeles
}

IS IT IN THE LIBRARY or the museum? For those of us who work in libraries, archives, or museums where collections occasionally overlap and cross over, this is a frequent question to which one could respond with another question: does it really matter? Rather than trying to answer this question directly, I will instead describe specific objects and exhibition contexts in which library, archival, and museum collections have enjoyed notably positive encounters.

Although it is located on the campus of the Getty Center in Los Angeles alongside the J. Paul Getty Museum, the Research Library at the Getty Research Institute identifies itself as an art research library, not a museum library. At the Research Library, collection curators understand that providing access to the collections and promoting them to new audiences is an integral part of collection development. A major part of curatorial work is not only to acquire and manage the collections, but also to publicize and interpret them through exhibitions, lectures, classes, publications, public programs, and symposia. As the Head of Collection Development, which is the curatorial department at the Getty Research Institute, I combine the perspectives of an art librarian, a rare-book curator, and an art historian who specializes in the history of illustrated books, prints, and maps. As collection curators at the Research Library, my colleagues and I collaborate with Getty Museum curators frequently, and progressively more Getty Museum exhibitions include library and archival materials.

An excellent example of this type of collaboration was seen at the 2005 opening exhibition for the Getty Villa, Antiquity \& Photography: Early Views of Ancient Mediterranean Sites. It featured numerous items from Getty Research Institute collections, including photographs and prints, as well as books that were illustrated with prints and photographs from the latter part of the nineteenth century, when photography was beginning to supplant printmaking as the popular illustrative medium. Considering that this exhibition marked the completed renovation of the Getty Villa, which features collections of antiquities, it is noteworthy that its curators (led 
by Claire L. Lyons, Collections Curator for Archaeology at the Getty Research Institute) drew on works held by the Getty Museum's Department of Photographs as well as the Special Collections of the Research Library. In my experience, this type of collaboration reflects a new trend in museum exhibitions that signals a growing appreciation for the documentary and historical materials held by special collections in libraries and archives. In the nearly nine years since the Research Library at the Getty Research Institute opened at the Brentwood site in December 1997, we have experienced steady increases in loans of books, archival materials, photographs, and other objects from our Special Collections to museums throughout the United States and occasionally abroad. To me, the wide range in types of institutions and exhibitions to which we lend items suggests that distinctions between institutional categories and collecting patterns are becoming fuzzier all the time.

This blurring of boundaries can be seen in many ways. Institutions are no longer so exclusive about what they collect; indeed, they are becoming ever more inclusive. For example, the artist's books of Ed Ruscha, the American painter and photographer, are now held and exhibited by both libraries and museums. Books such as Every Building on the Sunset Strip, Colored People, and Thirty-four Parking Lots in Los Angeles are increasingly valuable and sought after on the art market. Another example is the work of the photographer William Wegman. His To the New Gallery (1993) traces the circuitous path from the old to the new location of the Holly Solomon Gallery in New York City. Executed in red and black magic marker, the image can be viewed not only as a map but also as a set of visual instructions. Likewise, Water Yam (1963), by the Fluxus designer and inventor George Brecht, represents a set of printed instruction cards for performance. All of these works were created by artists who questioned the authority of museums, galleries, and art critics: should they be considered documents, or art? Should they be viewed only through glass cases or mylar folders? Personally, I prefer to see these types of materials kept and used in library settings rather than taken out of circulation and entombed following traditional museum practices.

The nature of postwar documentation cuts across art and documentary categories. Printed ephemera and related works on paper, such as the Wegman map, are marking new territories and objects—-published and unpublished-for art libraries and other types of research libraries to collect. Meanwhile, preparatory sketches, performance scores, instruction drawings, and conceptual art works where the instructions or descriptions of the project are the art-all materials that were formerly considered "archival"- are now collected by museums.

Images and media can also cross over and blur boundaries. Photographs, for example, can be regarded as both documents and art. In Agitated Images: John Heart- 


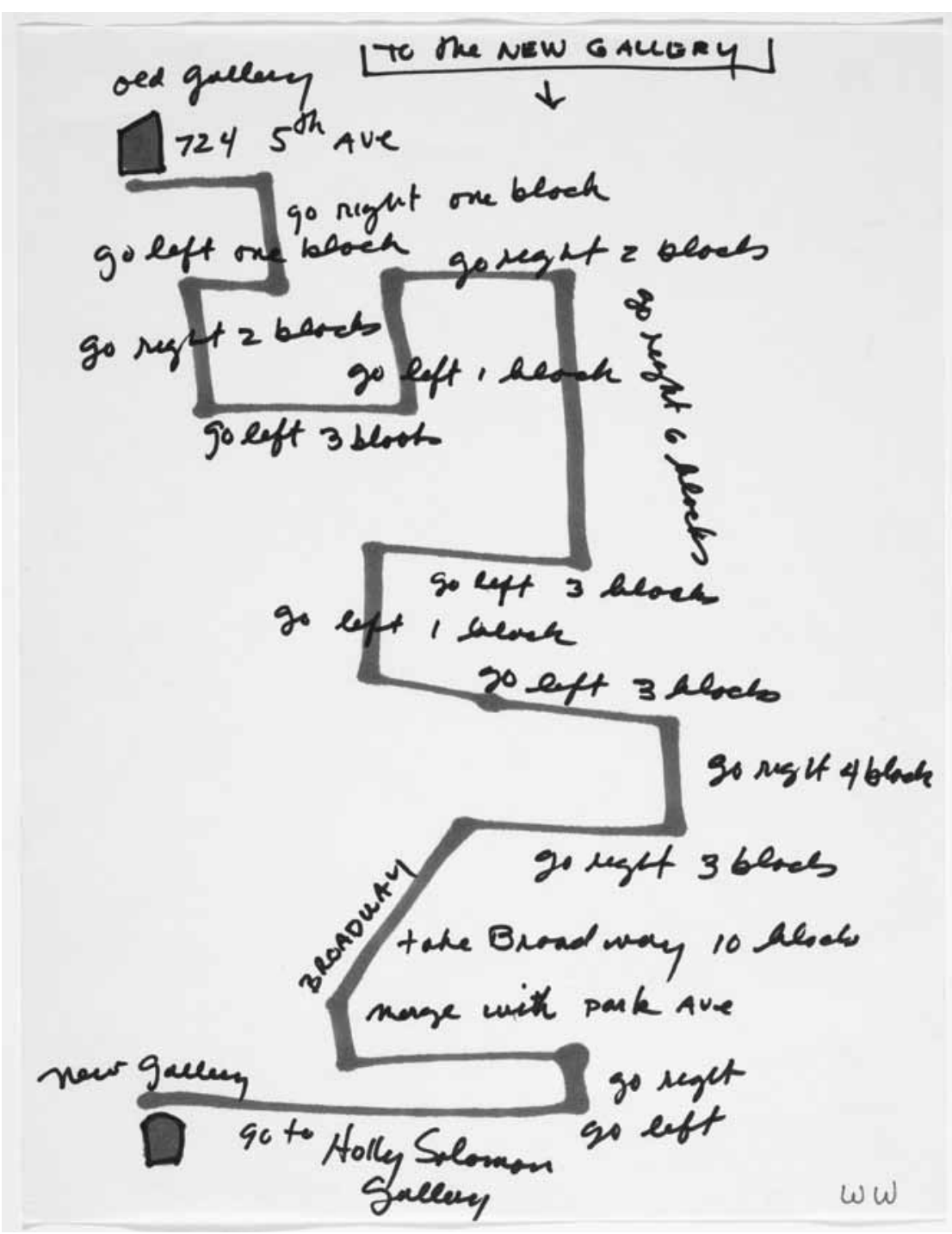

Figure 1. William Wegman, To the New Gallery (1993). With permission of the artist and the Getty Research Institute.

field and German Photomontage, 1920-1938, featured documentary photography and photomontage in a 2006 exhibition mounted at the Getty Research Institute Gallery. While other exhibitions on the Nazi-era brothers John Heartfield and Wieland Herzfeld had focused almost exclusively on their posters and individual photomontage creations, the Getty exhibit explored their art and design work for journals and books that were extraordinarily and effectively critical of Hitler's regime. Earlier exhibits and catalogs had neglected to convey the context of the images in publications such as the periodical Die Arbeiter-Illustrierte Zeitung or on the dust jackets of books published by Malik Verlag. 
Yet, on occasion, as I listen to myself explaining carefully that the Getty Research Institute does not collect art but rather documentation, I can feel myself begin to smile. Such a distinction no longer seems to be all that useful or even possible to delineate, either to us as curators-proposing acquisitions and shaping collections-or to the public, for whom we describe and present collections. In research library settings, documents or other special collections materials should always be collected for their potential value to research. Rather than "closing the case," as it were, exhibitions should continuously seek to stimulate new viewers and researchers to pursue new ideas.

Two recent exhibitions, both mounted in Los Angeles in 2001, broke new ground on several levels. Though differing greatly from one another in content and context, each enjoyed notable success. Their popularity and broad appeal was arguably attributable to the innovative characteristics they shared, including a highly eclectic selection of materials and objects, the deliberate choice to display "library" and other nonart objects in a museum setting, their inventive installation designs, and their extensively illustrated and creatively designed scholarly catalogs, both of which won awards. On their closing days, both exhibitions were crowded with many return visitors_an important measure of audience impact.

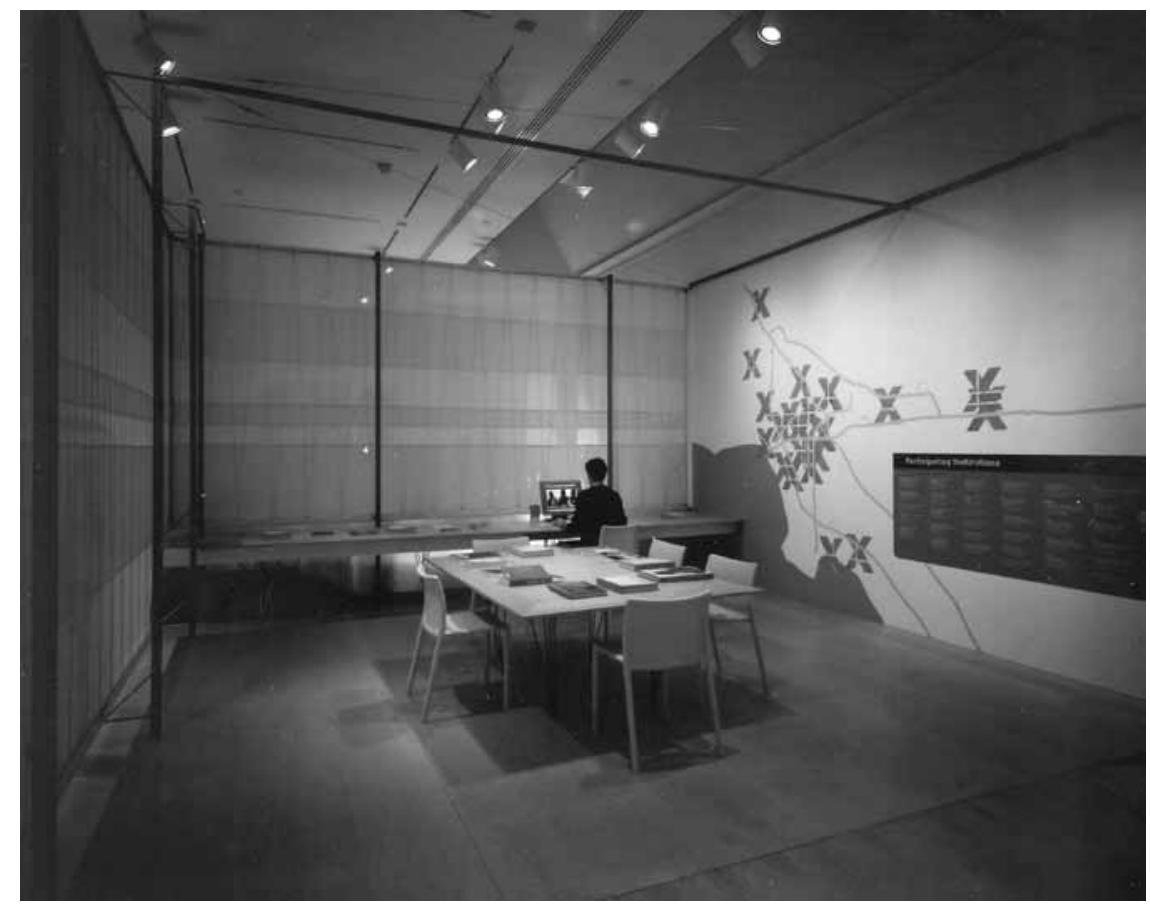

Figure 2. Installation view of The World from Here: Treasures of the Great Libraries of Los Angeles, Hammer Museum, Los Angeles. October 17, 2001-January 13, 2002. Photo by Joshua White. With permission of the Hammer Museum. 


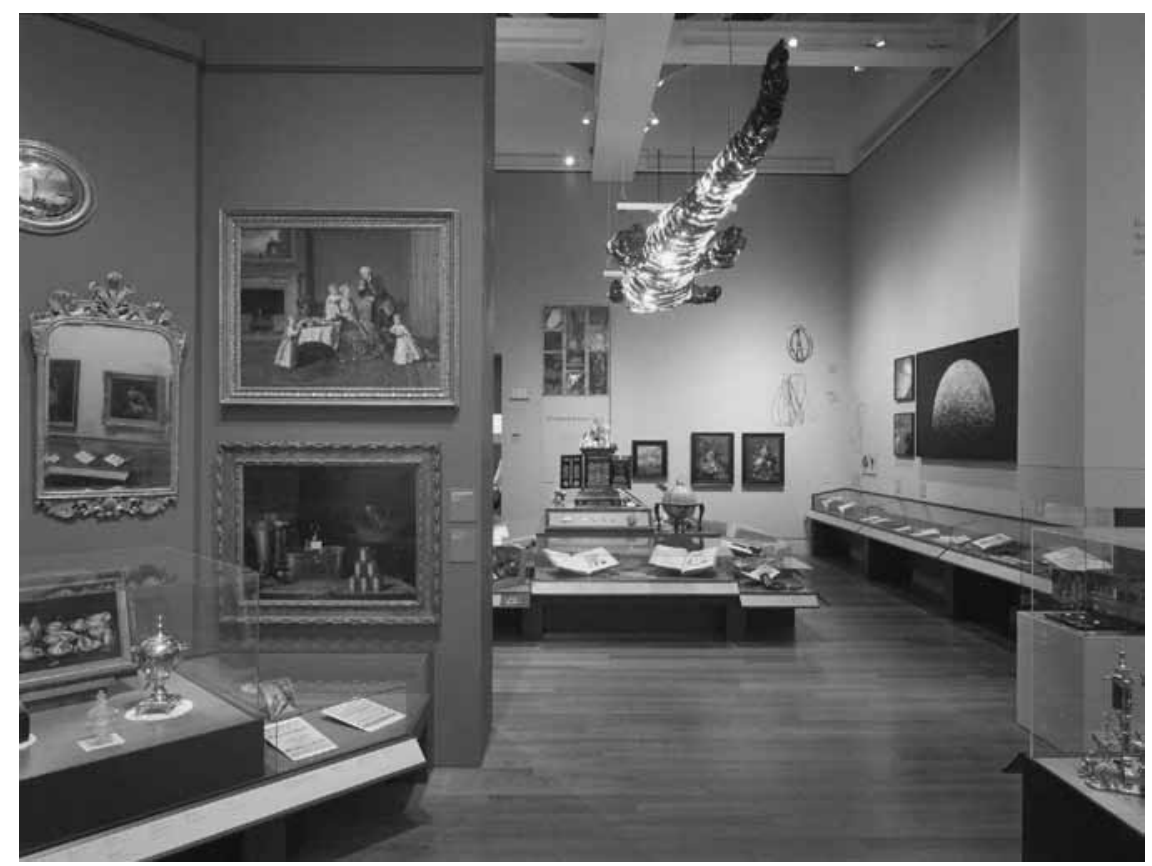

Figure 3. Installation view of Devices of Wonder: From the World in a Box to Images on a Screen, J. Paul Getty Museum, Los Angeles. November 13, 2001-February 3, 2002. Photo by Jack Ross and Anthony Perez. With permission of the J. Paul Getty Museum and the Getty Research Institute. (C2001, J. Paul Getty Trust.

The World from Here was an exhibition presented at the Armand Hammer Museum in Los Angeles as a collaborative library exhibition in a museum space. Organized by Bruce Whiteman (William Andrews Clark Library at the University of California at Los Angeles) and Cindy Burlingham (Hammer Museum), it was an effort to showcase not only the great treasures of libraries in Los Angeles but also the characteristic diversities of the participating institutions. The exhibition was funded primarily by a grant from the Institute of Museum and Library Services (IMLS), with additional assistance from other sponsors. Organized thematically, the groupings did not delineate the usual treasure-show categories, such as incunables, botanical books, and fine printing, although some examples of each of these types were included. Instead, because there had always been a sense that the culture and collections of Los Angeles were underappreciated and underpublicized, one important aim of the exhibition was to bring the resources of libraries and special collections of Los Angeles into focus by specifically designing the exhibit to showcase the materials in appealing ways, and with striking presentations. For example, a map in the special exhibition reading room was used to show the locations of the contributing libraries in the Los Angeles region. The copious printed catalog mirrored the exhibition's structure and its graphic design. 
Devices of Wonder: From the World in a Box to Images on a Screen was a Getty Center exhibition curated by Frances Terpak (Research Library, Getty Research Institute) and Barbara Maria Stafford (University of Chicago). Developed around a collection of precinematic objects, optical devices, and works on paper such as dioramas and paper theaters, it was intended to attract wide-ranging audiences from children to adults, and novices to experts. As with The World from Here, an important goal was to promote area collections with loans from institutions such as the Norton Simon Museum at the University of California at Los Angeles, the Los Angeles County Museum of Art, and the Los Angeles County Natural History Museum, as well as private collectors, including a local magician, Ricky Jay. A large show installed in the temporary galleries of the J. Paul Getty Museum, it drew record-breaking crowds and many return visitors. Numerous programs were organized around featured themes. Very much a multimedia event, the exhibition sought to replicate the wondrous experience of a collector's cabinet of curiosities from earlier centuries. Books and prints were displayed together with large objects, mirrors, silverware, and furniture - thus crossing and mixing media, genres, and periods.

One might charge that these exhibitions were overwhelmingly ambitious. Indeed, they took considerable time and energy. Yet they proved conclusively how museums, archives, and libraries can collaborate productively and fruitfully to bring diverse collections to new audiences. Ingenious selections, stimulating comparisons, arresting groupings and design, and - most important-confident interpretations incorporating appropriate and meaningful context, historical information, and engaging narratives, ultimately worked to encourage viewers to read and explore according to their own interests.

\section{AUATIED:DOBILE LITERATURE 1900-1975}

I buy sales brochures, repair \& owner's manuals, books, showroom items, artwork, models \& toys, posters or any items pertaining to automobiles, trucks or motorcycles... I travel to purchase collections.

Walter Miller 6710 Brooklawn Pkwy. Syracuse, NY 13211 USA $315-432-8282$ fax 315-432-8256 e-mail:info@autolit.com

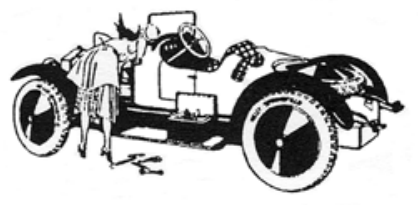

